Cite this article: de Lusignan S, Pearce $\mathrm{C}$. Time to mandate systems that promote collaborative working with computerised medical record systems, at a time of general practitioner shortage. J Innov Health Inform. 2018;25(4):260-262.

http://dx.doi.org/10.14236/jhi.v25i4.1140

Copyright ( 2018 The Author(s). Published by BCS, The Chartered Institute for IT under Creative Commons license http://creativecommons.org/licenses/by/4.0/

Author address for correspondence:

Simon de Lusignan

Professor

Department of Clinical and Experimental Medicine University of Surrey

Guildford GU2 7XH, UK

Email: s.lusignan@surrey.ac.uk

Accepted December 2018

\section{Time to mandate systems that promote collaborative working with computerised medical record systems, at a time of general practitioner shortage}

\author{
Simon de Lusignan \\ Professor, Primary Care and Clinical Informatics, University of Surrey, UK \\ Christopher Pearce \\ President, Australasian College of Health Informatics, University of Melbourne, Australia
}

\section{INTRODUCTION - A TIME OF GP SHORTAGE}

When we started as general practitioners (GPs), we did much more collaboratively. We sat as a group of clinicians for morning coffee or lunch, recounted about clinical consultations and worked through the similar data as now, albeit smaller volumes. The letters we worked through could be categorised into blood and other test results, prescriptions, letters and other miscellaneous requests. How to deal with a problem took into account who the person was and your colleague's heuristics about clinical management. This was collaborative medical work. At that time it was also easier to phone consultant colleagues and we even went into hospitals to visit patients admitted to the hospital, though admission duration was much longer then.

Primary care internationally is computerising and the UK and Australia provide examples of countries with high levels of computer use and the challenges of recruiting and retaining the GP workforce. Across the globe, GPs are working harder, for a combination of reasons, including patient factors (ageing population with more multimorbidity), health system factors (more information flowing into general practice), supply-side factors (including shortages in key roles) and even the demands of computers themselves. We present our typical working days in primary care and how many of these are just us and our computer and the time available for professional collaboration.

\section{COLLABORATIVE WORKING WITH CMR SYSTEMS}

Insufficient thought has been given to promoting collaborative working with computerised medical record (CMR) systems. The collaborative nature of medical work and the learning from discourse within the team was well described by Berg. ${ }^{1}$ In particular, he foresaw that we needed CMR systems that better meet the needs of health care workers. Many have recognised that case discussions between clinicians are an important part of learning, with no widespread adoption of other technologies to replace this dialogue. ${ }^{2}$ By design, many CMR systems block the collaborative affordances of the paper record, for example, simultaneous viewing or superimposed synchronous or asynchronous discussion or annotation, which has the status of exploratory discussion. ${ }^{3}$ Social media are well-established, but as yet there is a very little exploration of how these technologies might be used to enhance case discussion. 


\section{MANY HOURS OF LONE DOCTOR- COMPUTER INTERACTION}

Our typical practices days involve extensive work that can be isolating: they involve a lot of GP-computer hours and tasks previously done collectively are now done in isolation. Activities that once could and were maybe better carried out in a collaborative environment include

1) Reviewing and taking action on receipt of laboratory results.

2) Authorising prescriptions for people on long-term medicines.

3) Reading, highlighting for coding and creating actions that arise from the hospital, specialist and other letters.

4) Other administrative tasks that aren't in one of the three categories above, these might include response to requests for advice from specialists (in England via formal 'Advice and Guidance' electronic link), medical reports for third parties and other ad hoc requests.

There is also face-to-face and telephone consulting. This also involves using the computer but this appears to be for a fixed proportion of the consultation. ${ }^{4}$ Our full day's breakdown is shown in Table 1.

\section{COLLABORATIVE REMOTE WORKING MIGHT HELP}

Computers have been designed to support the patient/doctor dyad - but this should now be extended to take into account the full scope of clinical-computer interactions. Our computer systems 'know' how long we are using them and they could record how many hours of use. They could be a platform for collaborative interactions, including off-site working, by a clinical workforce that did not need to be within our building to complete these tasks. Our preference would not be to move to remote clinicians with no investment in those patients or that community; as context, both psychological and social dimensions are so important in understanding an individual's health and disease. ${ }^{5}$

\section{SUMMARY}

Whilst the computerisation of primary care has had many advantages, it is also associated with a time of altering GP workloads. It is plausible that better collaborative working could have a positive effect on sustaining the existing workforce, as well as introducing efficiency into our current ways of working.

Enhancing collaborative working might help reduce the isolation of clinicians working alone with their computer systems,

Table 1 Working with your computer in primary care

\begin{tabular}{|c|c|c|c|c|}
\hline Time & UK GP example & $\begin{array}{l}\% \text { usage } \\
\text { computer }\end{array}$ & Australian GP example & $\begin{array}{l}\% \text { usage } \\
\text { computer }\end{array}$ \\
\hline 07:30 & Results and correspondence & $100 \%$ & & \\
\hline 08:00 & & $100 \%$ & Results and correspondence checking & $100 \%$ \\
\hline 08:30 & Patient consultations & $40 \%$ & & $100 \%$ \\
\hline 09:00 & & $40 \%$ & Patient consultations & $40 \%$ \\
\hline 09:30 & & $40 \%$ & & $40 \%$ \\
\hline 10:00 & & $40 \%$ & & $40 \%$ \\
\hline 10:30 & Coffee break collaborative time & & & $40 \%$ \\
\hline 11:00 & Patient consultations & $40 \%$ & & $40 \%$ \\
\hline $11: 30$ & & $40 \%$ & & $40 \%$ \\
\hline $12: 00$ & & $40 \%$ & & $40 \%$ \\
\hline $12: 30$ & & $40 \%$ & & $40 \%$ \\
\hline 13:00 & Call back to patients and admin task & $75 \%$ & Admin Tasks - results etc. & $100 \%$ \\
\hline 13:30 & Possible home visit/Admin above & $50 \%$ & Lunch & \\
\hline 14:00 & Practice management time & & Patient consultations & $40 \%$ \\
\hline $14: 30$ & Prescription checking & $100 \%$ & & $40 \%$ \\
\hline 15:00 & Patient consults & $40 \%$ & & $40 \%$ \\
\hline $15: 30$ & & $40 \%$ & & $40 \%$ \\
\hline 16:00 & & $40 \%$ & & $40 \%$ \\
\hline 16:30 & & $40 \%$ & & $40 \%$ \\
\hline 17:00 & & $40 \%$ & & $40 \%$ \\
\hline $17: 30$ & & $40 \%$ & & $40 \%$ \\
\hline 18:00 & Prescription checking + letter review & $100 \%$ & Admin tasks - results, letter writing & $100 \%$ \\
\hline 18:30 & & $100 \%$ & & $100 \%$ \\
\hline
\end{tabular}


as well as enable much more remote part-time working. However, our preference would be in a way that enhances continuity of care, albeit at the natural size of that community. It might even stop some doctors hating their computers. ${ }^{6}$

\section{REFERENCES}

1. Berg M. Medical work and the computer based patient record: a sociological perspective. Methods of Information in Medicine 1998;37(03):294-301. doi: 10.1055/s-0038-1634535

2. Nilsen LL. Collaboration and learning in medical teams by using video conference. Behaviour and Information Technology 2011;30(4). doi: 10.1080/0144929X.2011.577193

3. Bardram JE, Houben S. Collaborative affordances of medical records. Computer Supported Cooperative Work (CSCW) 2018;1:1-36. doi: 10.1007/s10606-017-9298-5

4. Kumarapeli $P$, de Lusignan $S$. Using the computer in the clinical consultation; setting the stage, reviewing, recording, and taking
Sophisticated collaborative working has long been a feature of medical practice, and new collaborative working methods that in enabled remote working may have a role in both addressing the workforce crisis in primary care.

actions: multi-channel video study. Journal of the American Medical Informatics Association 2013;20(e1):e67-75. doi: 10.1136/amiajnl-2012-001081

5. Engel GL. The need for a new medical model: a challenge for biomedicine. Science 1977;196(4286):129-36. https://doi. org/10.1126/science.847460. PMid:847460.

6. GawandeA. Why Doctors Hate Their Computers. The NewYorker, 12 November 2018. Available from: https://www.newyorker. com/magazine/2018/11/12/why-doctors-hate-their-computers 